\title{
Extralobar pulmonary sequestration
}

This article was published in the following Dove Press journal:

International Medical Case Reports Journal

4 April 20II

Number of times this article has been viewed

\section{Albertas Ulys \\ Narimantas Evaldas \\ Samalavicius \\ Saulius Cicenas \\ Tadas Petraitis \\ Mantas Trakymas \\ Dmitrij Sheinin \\ Leonid Gatijatullin}

Institute of Oncology,

Vilnius University, Santariskiu,

Vilnius, Lithuania
Correspondence: Leonid Gatijatullin Institute of Oncology, Vilnius University, Santariskiu I, LT-08660, Vilnius, Lithuania Tel +3 7052786700

Fax +3 7052720164

Email cancer@vuoi.lt
Abstract: Prevalence of pulmonary sequestration accounts for up to $6.4 \%$ of all congenital pulmonary malformations. We report on a 40-year-old woman who underwent excision of an aberrant solid retroperitoneal mass in the left subdiaphragmatic area. The mass was identified to be an extralobar pulmonary sequestration. The diagnosis could be made without surgery by percutaneous tissue biopsy and imaging. We encourage keeping in mind pulmonary sequestration anomaly presenting as an aberrant retroperitoneal mass. The aim of this case report is to increase awareness about the condition and review the criteria for its definitive diagnosis and treatment.

Keywords: retroperitoneal aberrant mass, extralobar pulmonary sequestration

\section{Case report}

A 40-year-old woman was evaluated for abdominal pain, which had been present for two years. Abdominal ultrasound did not reveal any abnormalities. The patient had a history of endometriosis. Complete blood count, chemistry panel, urine analysis, and liver function tests were normal. Medical history, physical examination, and biochemical parameters did not suggest any dysfunction. Magnetic resonance imaging (MRI) and computed tomography (CT) of the abdomen showed a heterointensive $2.36 \times 8.53 \mathrm{~cm}$ aberrant enhancing mass in the projection of the left diaphragmatic peduncle (Figures 1A, 1B). Excision of an aberrant solid retroperitoneal mass was performed. Pathology revealed an extralobar pulmonary sequestration in the left retroperitoneum, with a brown elastic $4.7 \times 1.5 \mathrm{~cm}$ tumor. In sections, the multicameral tumor was filled with a whitish consistency substance. The tumor consisted of bronchioles lined by ciliated columnar epithelium and alveoli (Figures 2A, 2B). Three months later, a follow-up MRI revealed the residue of the retroperitoneal mass (Figure 3). There was no negative dynamic of mass residue three months after MRI imaging.

\section{Discussion}

Pulmonary sequestration was first described in 1861 by Rektorzik as an embryonic mass of lung tissue that has no identifiable bronchial communication and receives its own blood supply from an anomalous systemic artery with an origin at either the thoracic or abdominal aorta. ${ }^{1}$ Prevalence of pulmonary sequestration accounts for up to $6.4 \%$ of all congenital pulmonary malformations and $1.1 \%-1.8 \%$ of all pulmonary resections. $^{2}$ 

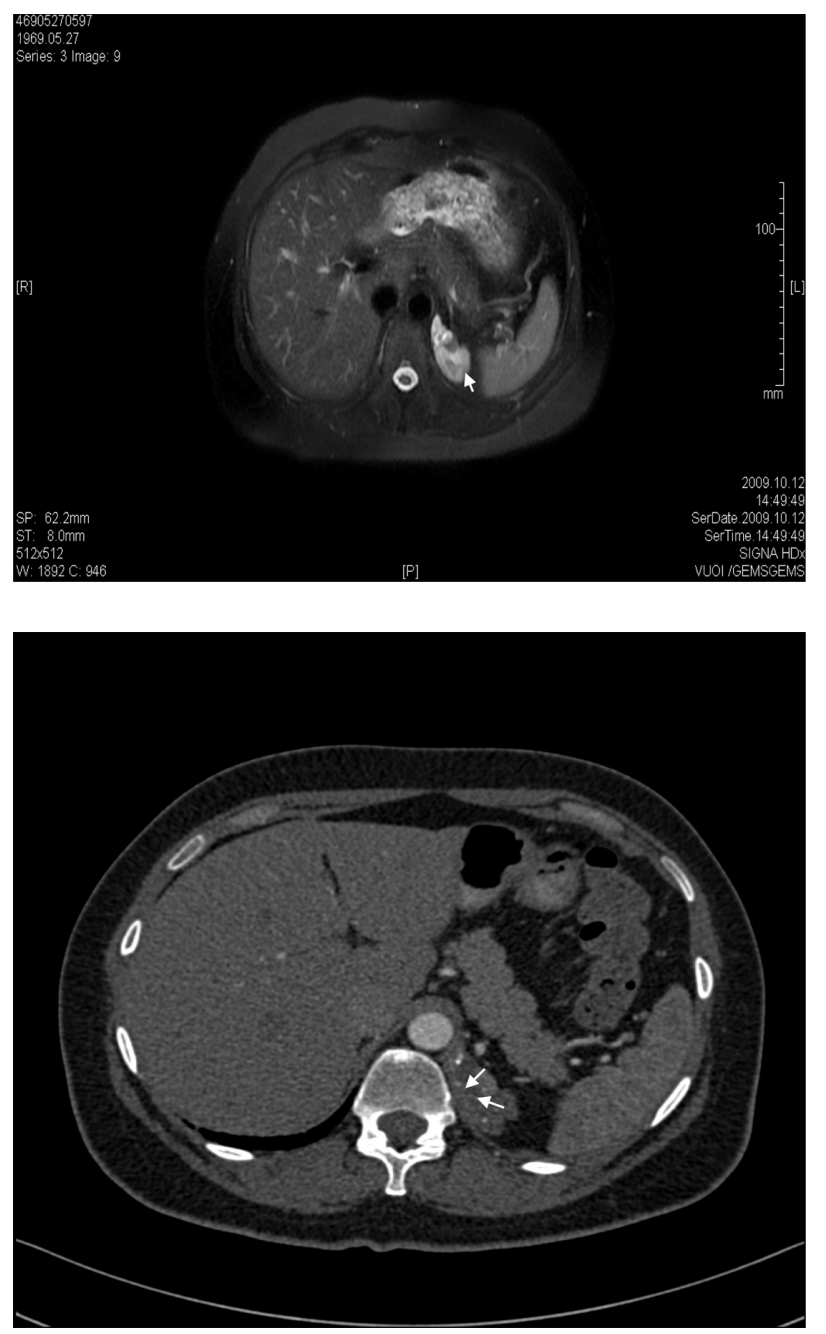

Figure I A) Magnetic resonance image of the undetermined retroperitoneal left subdiaphragmatic mass $(2.36 \times 8.53 \mathrm{~cm}$, arrow). B) Axial postcontrast arterial-phase computed tomographic image of undetermined retroperitoneal left subdiaphragmatic mass $(2.36 \times 8.53 \mathrm{~cm}$, arrows $)$ with small calcifications inside.

The sequestration is called extralobar because the mass lies outside the normal visceral pleura, and may also lie outside of the thorax in a subdiaphragmatic position. Extralobar pulmonary sequestration accounts for $14 \%-25 \%$ and intralobar pulmonary sequestration accounts for $75 \%-86 \%$ of cases. In extralobar pulmonary sequestration, males are affected approximately four times more often than females. Sixty-one percent of patients present when they are younger than six months of age. In $10 \%$ of cases, patients are asymptomatic at the time of diagnosis. ${ }^{2}$

Ideally, the diagnosis could be made without surgery by percutaneous tissue biopsy and imaging. ${ }^{3,4}$ However, computed tomography (CT)/magnetic resonance imaging (MRI) does not provide a conclusive diagnosis of extralobar pulmonary sequestration., ${ }^{3,4}$ The diagnosis of an intralobar pulmonary sequestration can be confirmed by enhanced
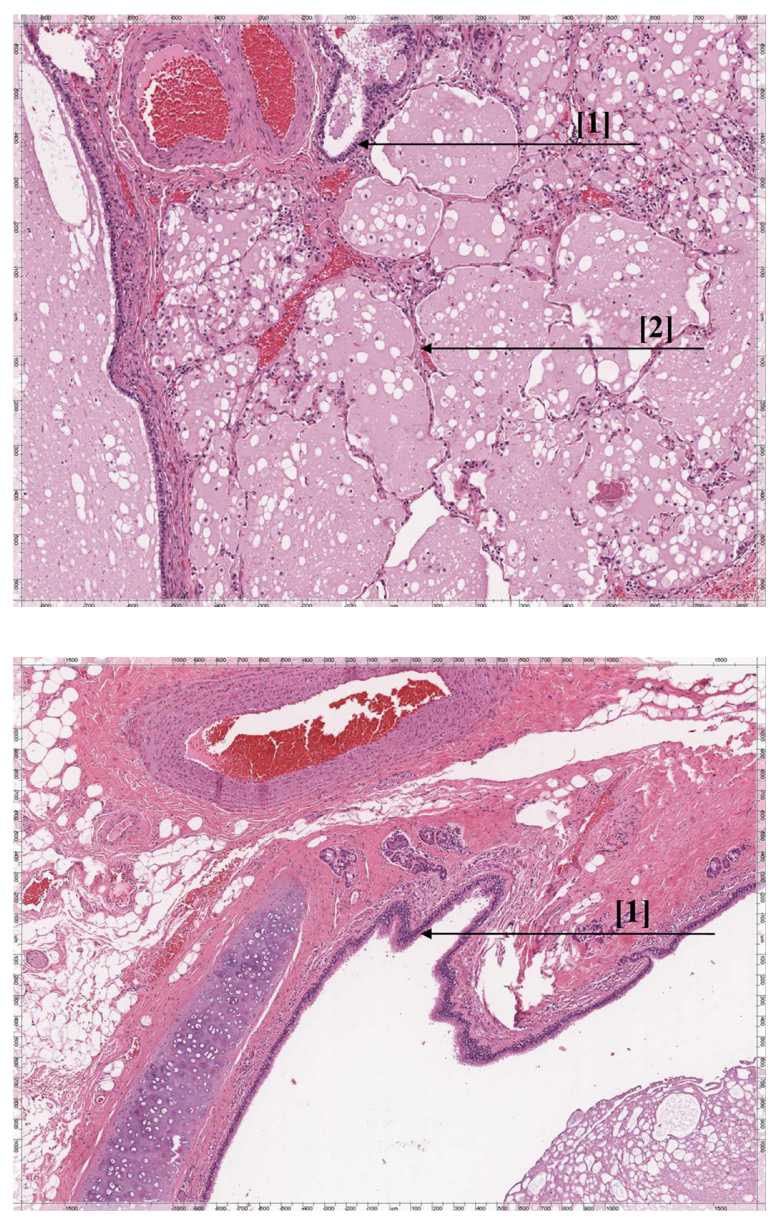

Figure 2 A) Histology specimen consisting of bronchioles (I) lined by ciliated columnar epithelium and alveoli (2). B) Histology specimen consisting of a bronchiole (I) lined by ciliated columnar epithelium.

contrast $\mathrm{CT}$ scanning with three-dimensional reconstruction, which is a noninvasive method. ${ }^{3,4} \mathrm{CT}$ scans have $90 \%$ accuracy in the diagnosis of pulmonary sequestration. ${ }^{3,4}$ Arteriography (conventional or CT angiography) is the gold standard for identifying pulmonary sequestration

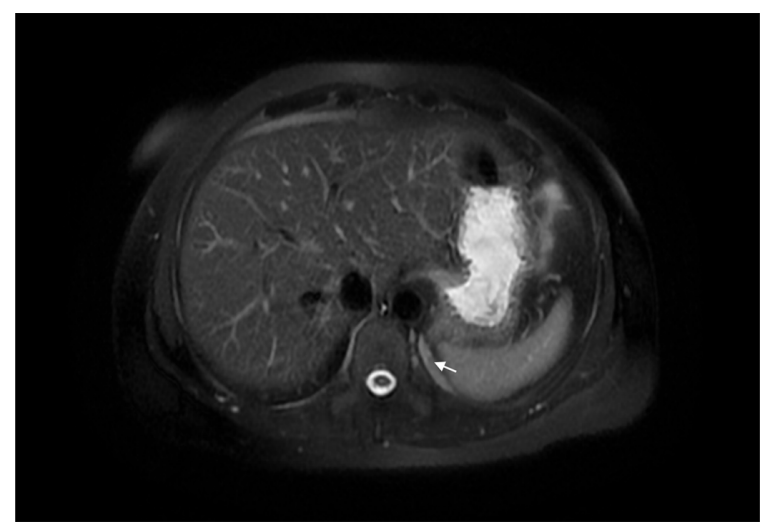

Figure 3 Magnetic resonance image of left retroperitoneal subdiaphragmatic region with mass residue (arrow). 
because it confirms the anatomy and identifies the systemic arterial blood supply. ${ }^{1} \mathrm{MRI}$ and MR angiography can provide information similar to that obtained by CT scans. ${ }^{5-8}$ Ultrasonography is noninvasive and safe, making its use ideal in the prenatal and postnatal settings. ${ }^{9-11}$ Color flow and duplex Doppler ultrasound can accurately depict the ectopic blood supply and drainage. ${ }^{12-16}$ Radionuclide angiography is another noninvasive technique that may demonstrate the systemic arterial blood supply to the sequestration, thus establishing the diagnosis. ${ }^{17,18}$

Management of an asymptomatic pulmonary sequestration with no connection to the surrounding lung is controversial. At present, open surgery remains the best approach to definitive resection for intralobar or extralobar sequestration. ${ }^{19}$ An alternative option to treat pulmonary sequestration is embolization of the feeding arteries. ${ }^{19}$

\section{Conclusion}

The gold standard for identifying pulmonary sequestration is angiography because it confirms the anatomy, identifies the systemic supply, and shows the venous drainage. It should be done to clarify the vascular supply to the pulmonary sequestration as an essential part of the preoperative assessment of such patients, due to the risk of occult or operative hemorrhage, and to identify the exact artery to be destroyed to remove any blood supply to the mass residue. We encourage keeping in mind pulmonary sequestration anomaly presenting as an aberrant retroperitoneal mass. Prompt suspicion of nonresolving radiological lesions is needed to enable correct and early diagnosis of pulmonary sequestration. Three months later, there was no negative dynamic of mass residue on MRI in our patient. In case of mass enlargement, artery embolization or surgery is indicated.

\section{Disclosure}

The authors declare that they have no competing interests in this work.

\section{References}

1. Prasad R, Garg R, Verma K. Intralobar sequestration of lung. Lung India. 2009;26(4):159-161.

2. Yucel O, Gurkok S, Gozubuyuk A, et al. Diagnosis and surgical treatment of pulmonary sequestration. Thorac Cardiovasc Surg. 2008; 56(3):154-157.

3. Salmons S. Pulmonary sequestration. Neonatal Netw. 2000; 19(7):27-31.

4. Amitai M, Konen E, Rozenman J, Gerniak A. Preoperative evaluation of pulmonary sequestration by helical CT angiography. Am J Roentgenol. 1996;167(4):1069-1070.

5. Ooi GC, Cheung CW, Lam WK, Tsang KW. Pulmonary sequestration: Diagnosis by magnetic resonance angiography and computed tomography. Chin Med J (Engl). 1999;112(7):668-670.

6. Fumino S, Iwai N, Kimura O, Ono S, Higuchi K. Preoperative evaluation of the aberrant artery in intralobar pulmonary sequestration using multidetector computed tomography angiography. J Pediatr Surg. 2007; 42(10): 1776-1779.

7. Sancak T, Cangir AK, Atasoy C, Ozdemir N. The role of contrast enhanced three-dimensional MR angiography in pulmonary sequestration. Interact Cardiovasc Thorac Surg. 2003;2(4):480-482.

8. Zhang M, Zhu J, Wang Q, Shang D. Contrast enhanced MR angiography in pulmonary sequestration. Chin Med J (Engl). 2001; 114(12):1326-1328

9. May DA, Barth RA, Yeager S, Nussbaum-Blask A, Bulas DI. Perinatal and postnatal chest sonography. Radiol Clin North Am. 1993;31(3): 499-516.

10. MacKenzie TC, Guttenberg ME, Nisenbaum HL, Johnson MP, Adzick NS. A fetal lung lesion consisting of bronchogenic cyst, bronchopulmonary sequestration, and congenital cystic adenomatoid malformation: The missing link? Fetal Diagn Ther. 2001;16(4):193-195.

11. West MS, Donaldson JS, Shkolnik A. Pulmonary sequestration. Diagnosis by ultrasound. J Ultrasound Med. 1989;8(3):125-129.

12. Smart LM, Hendry GM. Imaging of neonatal pulmonary sequestration including Doppler ultrasound. Br J Radiol. 1991;64(760):324-329.

13. Nicolini U, Cerri V, Groli C, et al. A new approach to prenatal treatment of extralobar pulmonary sequestration. Prenat Diagn. 2000;20(9):758-760.

14. Suga K, Hara A, Matsumoto T, et al. Intralobar bronchopulmonary sequestration: Evidence of air trapping shown by dynamic xenon-133 SPECT. Br J Radiol. 2001;74(883):657-661.

15. Newman B. Real-time ultrasound and color-Doppler imaging in pulmonary sequestration. Pediatrics. 1990;86(4):620-623.

16. Sauerbrei E. Lung sequestration. Duplex Doppler diagnosis at 19 weeks' gestation. J Ultrasound Med. 1991;10(2):101-105.

17. Gooneratne N, Conway JJ. Radionuclide angiographic diagnosis of bronchopulmonary sequestration. $J$ Nucl Med. 1976;17(12):1035-1037.

18. Lee BS, Kim JT, Kim EA, et al. Neonatal pulmonary sequestration: Clinical experience with transumbilical arterial embolization. Pediatr Pulmonol. 2008;43(4):404-413.

19. Osaki T, Kodate M, Takagishi T, Nomi M, Murakami J, Yamamoto H. Unique extralobar sequestration with atypical location and aberrant vessels. Ann Thorac Surg. 2010;90(5):1711-1712.
International Medical Case Reports Journal

\section{Publish your work in this journal}

The International Medical Case Reports Journal is an international, peer-reviewed open-access journal publishing original case reports from all medical specialties. Previously unpublished medical posters are also accepted relating to any area of clinical or preclinical science. Submissions should not normally exceed 2,000 words or

\section{Dovepress}

4 published pages including figures, diagrams and references. The manuscript management system is completely online and includes a very quick and fair peer-review system, which is all easy to use. Visit http://www.dovepress.com/testimonials.php to read real quotes from published authors. 